\title{
QUEEN'S
UNIVERSITY
BELFAST
}

\section{Emotional response to images of wind turbines: A psychophysiological study of their visual impact on the landscape}

Maehr, A. M., Watts, G. R., Hanratty, J., \& Talmi, D. (2015). Emotional response to images of wind turbines: A psychophysiological study of their visual impact on the landscape. Landscape and Urban Planning, 142, 71-79. https://doi.org/10.1016/j.landurbplan.2015.05.011

\section{Published in:}

Landscape and Urban Planning

\section{Document Version:}

Peer reviewed version

Queen's University Belfast - Research Portal:

Link to publication record in Queen's University Belfast Research Portal

\section{Publisher rights}

(C) 2015 Elsevier Ltd. This manuscript version is made available under the CC-BY-NC-ND 4.0 license http://creativecommons.org/licenses/bync-nd/4.0/which permits distribution and reproduction for non-commercial purposes, provided the author and source are cited.

\section{General rights}

Copyright for the publications made accessible via the Queen's University Belfast Research Portal is retained by the author(s) and / or other copyright owners and it is a condition of accessing these publications that users recognise and abide by the legal requirements associated with these rights.

\section{Take down policy}

The Research Portal is Queen's institutional repository that provides access to Queen's research output. Every effort has been made to ensure that content in the Research Portal does not infringe any person's rights, or applicable UK laws. If you discover content in the Research Portal that you believe breaches copyright or violates any law, please contact openaccess@qub.ac.uk. 
Emotional response to images of wind turbines: A psychophysiological study of their visual impact on the landscape

\author{
Anna M. MAEHR ${ }^{1}$, Greg R. WATTS ${ }^{2}$, Jennifer HANRATTY ${ }^{3}$, and Deborah TALMI ${ }^{4}$ \\ ${ }^{1}$ University of Manchester, anna.maehr@alumni.manchester.ac.uk \\ ${ }^{2}$ University of Bradford, g.r.watts@bradford.ac.uk \\ ${ }^{3}$ Queen’s University Belfast, j.hanratty@qub.ac.uk \\ ${ }^{4}$ University of Manchester, Deborah.Talmi@manchester.ac.uk
}

Address for correspondence:

Deborah Talmi. School of Psychological Sciences, University of Manchester. Coupland 1, Oxford Road, Manchester, M139PL, UK.

Email: Deborah.Talmi@manchester.ac.uk

Telephone: $\quad$ +44 (0) 1612751968 


\section{Introduction}

Energy supply is one of the leading causes of greenhouse gas emission (Pachauri \& Reisinger, 2007). Wind turbines have a low power production carbon footprint, and it has been suggested that by 2030 , half of the worldwide power demand could theoretically be covered by wind energy (Jacobson \& Archer, 2012). One challenge for wind turbine implementation is social acceptance. For example in the UK, $63 \%$ are in favour of wind turbines, $28 \%$ show balanced views, $5 \%$ oppose and $4 \%$ do not know (Kondili \& Kaldellis, 2012). Thus, technically sound wind energy projects may fail because of residential opposition.

Psychological research can contribute positively to the science of climate change (Swim et al. 2009). Historically, research on social acceptance of wind turbines has been conducted in a market-research manner (Devine-Wright, 2007), with limited academic peer reviewed research (McGowan \& Sauter, 2005). Our understanding of the determinants of attitudes wind turbines has developed since then. For example, Jones and Eiser $(2009 ; 2010)$ show that even when general attitude to wind turbines is progressive, specific attitudes to proposed development nearer to homes are usually more negative. Because the latter situations are more emotionally evocative, their findings demonstrates that psychological sciences and deeper understanding of psychological and physiological factors leading to wind turbine acceptance and opposition could be useful in the planning implementation stage. Similarly, the number of peer-reviewed papers on the effect of wind turbines on human health grew 6-fold between 2011 and 2014(Knopper and Ollson, 2011; Knopper et al., 2014). Knopper et al.’s review was also suggestive of the key role 
of psychological factors above and beyond objective impact of wind turbines' noise and operational effects.

The visual impact of wind turbines on the landscape plays a significant role in attitudes towards this technology (Wolsink, 2000). A recent review (Knopper et al., 2014) concluded that "when sited properly, wind turbines are not related to adverse health effects", but that subjective reports of detrimental health impact have more to do with "visual cues and attitudes". This conclusion is supported by the findings that visual aspects can influence the perception of noise from wind turbines (Maffei et al., 2013) and that when turbines are located 'out of sight' they are more acceptable (Jones \& Eiser, 2010). Similarly, De Vries, de Groot \& Boers (2012) found that participants generally perceived wind turbines as negative man-made structures and that closeness to turbines and landscape beauty influenced the perceived impact, and Pedersen and Persson (2007) suggest a link between perception of turbines as 'ugly' and annoyance. This may be because turbines reduced the restorative attributes of landscape images (Chang et al., 2008). Indeed, wind turbines have been shown to reduce tranquillity as shown by the relatively low ratings given by jury members' evaluations of a 50m high installation (Watts and Pheasant, 2013). The current study extends this research by focusing on the emotional domain and analysing psychophysiological reactions to wind turbines using photo manipulated pictures. When it comes to judging the visual impact of wind turbines, supporters and opponents pay attention to different details. While supporters focus on benefits, such as environmental values, opponents mostly see the negative effects, for example a "disharmony" with the landscape (Krohn \& Damborg, 1999). Anger and surprise, which may characterise opponents (Cass \& Walker, 2009), are associated with bodily reactions (Jasper, 1998). These emotional reactions are mostly manifested as increased activation of the sympathetic nervous system; a system that 
predominantly responds to sudden changes in the environment, such as a threat or an injury, and prepares the body for a fight-or-flight reaction. Consequently a number of physiological changes are initiated, including changes in heart rate and increase in sweat secretion (Kandel, Schwartz, \& Jessell, 2000). The conductance of the skin gradually increases with self- reported emotional arousal (Lang, Greenwald, Bradley, \& Hamm, 1993).

Current literature on wind turbine opposition is limited because it relies on data from questionnaires and interviews, which are often influenced by factors beyond the emotional response itself, such as beliefs about the efficiency of this technology (Krohn \& Damborg, 1999). Differences between reported and felt emotions could arise, on the one hand, when questionnaires are answered by individuals who are directly affected by an upcoming installation, where responses may be more goal-directed. On the other hand, Jones and Eiser's $(2009,2010)$ data on the difference between general attitudes and specific attitudes to wind farms closer to home suggest that attitudes reflected in questionnaires and interviews may change when people are confronted with a wind turbine environment. Here we propose a novel method for assessing to assess attitudes to wind turbines. Skin conductance changes are not under voluntary control and therefore could provide an objective index of the emotional reaction (Smith \& Ellsworth, 1985). To date, no study has used a psychophysiological approach to quantify objectively the intensity of emotions associated with the visual impact of wind turbines; this was the goal of the current experiment.

The current study investigated physiological responses to pictures of wind turbines against a range of rural scenes. Looking at pictures is very different from experiencing events, but their symbolic threat is sufficient to trigger an emotional arousal response and a concomitant sympathetic reaction, including skin conductance responses (SCRs) (Bradley, Codispoti, 
Cuthbert, \& Lang, 2001; Chang et al., 2008; Lang et al., 1993). Chang et al. (2008), for instance, found an increase in alpha frequency when participants viewed natural scenes judged to be 'restorative'. Clearly, still images do not capture the full visual impact of wind turbine. Nevertheless blade rotations may be assumed by viewers such that any assessed impacts may provide a reasonable indication of operating turbines. Still images also do not capture the noise produced by turbines, which also contributes to wind turbine opposition (Knopper et al., 2014). However, this soundscape aspect has already been well researched (Fiumicelli, 2011) and it has been found that visual aspects affect noise perception of wind turbines (Maffei et al., 2013).

We hypothesised that landscapes with wind turbine will generate stronger SCRs than control sceneries, but lower SCRs than aversive pictures selected to evoke negative emotions (e.g. war scenes, bee sting). Churches were chosen as control images because, like turbines, they are prominent, man-made environmental stimuli, but unlike turbines, they are familiar, usually not controversial, and have been shown to have little or no detrimental effect on the tranquillity of the countryside (Pheasant, Watts \& Horoshenkov, 2009). Other familiar, man-made environmental stimuli associated with energy production were used as additional controls. We distinguished between participants who were for and against wind turbines with a novel questionnaire, and further hypothesised that wind turbines would be associated with stronger SCRs than control sceneries, and that this difference would be stronger for opponents.

We also collected subjective self-report data on participants' emotional arousal and the valence of these emotions. Valence ratings are important because SCRs and arousal ratings do not reflect the degree of pleasure or displeasure associated with viewing pictures (Bradley, Cuthbert, \& Lang, 1990). We hypothesized that turbines will be rated as more arousing and more negative than control images and that this effect will grow for opponents. 


\section{Methods}

\subsection{Participants}

60 University of Manchester undergraduate students (54 female, 6 male) aged 18 - 35 (mean age $\mathrm{M}=20.67$, standard deviation $\mathrm{SD}=2.92$ ) completed the online questionnaire for course credits. Respondents were ranked by their degree of wind turbine support. 30 participants with the higher and lower scores were classified as supporters or non-supporters and invited to participate in the subsequent laboratory study for course credits or reimbursement (£7). 23 took part and 21 completed the study, one was excluded because of a skin condition and one because of a fire alarm. The study was approved by the local Research Ethics Committee and participants gave written informed consent. All participants were fluent English speakers, had normal or corrected-to-normal vision and no history of mental illnesses or neurological problems.

\subsection{Materials}

Wind attitude questionnaire. A new questionnaire consisting of nine wind turbine related questions and six more general questions (asking about other energy sources, churches or pylons) was constructed (see Table 1). Five questions directly assessed attitudes towards wind turbines. Because there is evidence for a relationship between environmental protection priorities and attitudes towards renewable energy (Poortinga, Pidgeon, \& Lorenzoni, 2006; The Department of Trade and Industry, 2003; but see London Renewables, 2003, as cited in Devine-Wright, 2007) two general questions about environmental concerns were included. One question asked about 
their self-assessed knowledge about renewable energy, and another one about their familiarity with wind turbines. Participants answered using a 5-point rating scale.

Picture stimuli. 10 images of wind turbines, churches, pylons and power plants and 10 landscape pictures were obtained using Google image search. None of the images were copyrighted. These lanscape pictures varied along a continuum from managed to unmanaged land. Figure 1 depicts examples of the pictures used. Each object was inserted into each of the 10 landscape pictures using Gimp 2 software, yielding 40 pictures. The stimuli were counterbalanced for size and position within the background by grouping them into 3 different size scales and 3 spatial positions. Size was defined by the proportion of picture height that was occupied by the stimuli, whereby heights less than $30 \%$ represented small, between $30 \%$ and $40 \%$ medium and more than $40 \%$ large stimuli. Spatial position was classified as the left, middle or right third of the picture. We also computed the percentage surface area occupied by the object in relation to the whole picture. On average, churches occupied $4.9 \%$, power plants $3.6 \%$, pylons $2.4 \%$, and turbines $0.75 \%$. The difference between the objects was not statistically significant $(F(3,36)=1.8, p>0.15)$ although the smaller surface area of turbines, which are narrower than other constructions, should be born in mind. Ten aversive control pictures were obtained from the same source or the International Affective Picture System (IAPS, Lang, Bradley, \& Cuthbert, 2008) and depicted disturbing scenes of varying intensities: an empty wallet, a slug, a broken mobile phone, a nail scratching a blackboard, a bee sting, a person slipping on ice, people holding guns, a man pointing a gun to a child, a woman in distress and an injured baby in hospital. All images are available upon request.

Rating-scales. Valence and arousal were rated on a 9-point scale using the SelfAssessment Manikin (SAM) scale (Bradley \& Lang, 1994), a widely used rating scale that uses 
figures to allow participants to indicate how they feel on these dimensions; for example, valence is rated using figures with an upturned mouth (happy), a straight mouth (neutral), to a downturned mouth (unhappy, Figure 2). Ratings of tranquillity on a 0 to 10 scale (Watts \& Pheasant, 2013) were also obtained and will be reported separately (Watts, Maehr \& Talmi, in preparation). Mood was measured using three 9-point Likert scales which covered the dimensions happiness (ranging from happy to unhappy), anxiety (ranging from anxious to calm) and despondency (ranging from despondent to cheerful). Mood ratings were introduced to ensure participants were not unduly distressed by the aversive pictures, and data from them was not analysed further.

\section{Apparatus.}

Skin conductance response measurements were recorded using a constant voltage system (0.5Volts) and $\mathrm{Ag} / \mathrm{AgCl}$ cup electrodes with a $10 \mathrm{~mm}$ diameter, both manufactured in-house. Measurements were recorded with a 1401 plus data acquisition system (Cambridge Electronic Designs, Cambridge, UK) and digitized using Spike2 software (Cambridge Electronic Designs, Cambridge, UK). Temperature and humidity in the laboratory were recorded and ranged between 21 and 24 degrees Celsius and $28 \%$ and $40 \%$, respectively.

\subsection{Procedure}

Participants in the initial Questionnaire study signed up for the study using the University's sign-up system and completed the questions online. Laboratory study participants were tested individually in a quiet room by an experimenter (the first author) who did not know 
them personally and was blind to their attitude towards wind turbines. After giving written consent, the electrodes were filled with a water-based gel and affixed to the ventral portion, middle phalanx of digits 2 and 4 of the left hand of each participant. Participants were asked to place their arm on an arm rest and to keep it still throughout the experiment. They were then given instructions on how to rate valence, arousal and tranquillity, and practiced rating five

practice pictures. To minimize movement artefact in the SCR measurement participants gave their rating by pointing to the relevant location on a printed copy of the scales, located next to their right hand; these responses were recorded by the experimenter who sat next to the participant for the duration of the experiment. The light was then switched off and the 50 pictures were presented in a pseudorandomized order, with no more than 2 pictures from the same condition appearing consecutively. Participants were instructed to look at the picture the entire time it was displayed. Figure 2 describes schematically what a single step of picture viewing and ratings looked like. To prevent fatigue a break of self-determined duration was given in the middle of the sequence. Participants filled out the mood rating before and after the experiment; no participant reported a marked change in mood.

\section{Results}

\subsection{Questionnaire study}

The 9 items in the questionnaire were originally generated to assess attitudes to wind farms and wind power along with one question each on knowledge of renewable energy and concern about the environment (see Table 1). Responses on the questionnaire were translated into numbers, whereby high numbers stand for high wind turbine support. Table 2 provides 
descriptive statistics for these items. Exploratory factor analysis was initially carried out on the responses to these original items. Inspection of the scree plot and eigenvalues in the exploratory factor analysis (Figure 3) indicated that a three factor solution was appropriate. Confirmatory factor analysis (a principle component analysis with direct oblimin rotation; the same results were obtained with varimax rotation) was then carried out. Inspection of the items loading on each factor showed that only one of the three factors was interpretable. This factor had three items with loadings above 0.70 . These items were "I find the appearance of wind farms within a landscape acceptable", "I would be concerned if a wind turbine would be built in my neighbourhood [reverse coded]" and "wind turbines spoil the views in many rural areas [reverse coded]". This factor was therefore considered to measure attitudes to wind farms in the landscape with good face validity. Split half reliability was acceptable for this small sample size with Cronbach's alpha of.68. The remaining two factors were not interpretable as the items loading on these factors did not appear to relate to identifiable underlying concept/latent variable. The average of the wind attitude score $(M=3.35, S D=1.05)$ indicated a slightly favourable attitude towards wind turbines in our sample.

Table 2 depicts the correlation between questionnaire items. Interestingly, the wind attitude score correlated positively with score on the question 'Protecting the environment is one of my biggest concerns' $(r=.39, p<.01)$ and with the statement 'I consider myself to be knowledgeable about renewable energy' $(r=.32, p<.01)$, which were themselves positively correlated $(r=.58, p<.001)$.

Participants above the median wind attitude score $($ Median=3.33) were deemed 'supporters' and those below this score were deemed 'non-supporters'. The wind attitude scores of 11 supporters $(\mathrm{M}=4.42, \mathrm{SD}=.12)$ and 10 non-supporters $(\mathrm{M}=2.5, \mathrm{SD}=.19)$ who participated in 
the laboratory study differed significantly from each other as evident in a significant student ttest, $\mathrm{t}(17)=8.43$, where the probability that the null hypothesis is true ( $p$-value, or simply $p$ ) was smaller than .001 . The effect size $(d)$ of this comparison equalled 3.87, a large effect according to Cohen's classification scheme (Cohen, 1988).

\subsection{Laboratory study}

SCR was defined as the difference between the lowest and highest conductance value (measured in microsiemens) within a 1 to 5 second time frame after picture presentation. Arousal and valence ratings were highly reliable (both Chronbach alphas .94). The rating of valence and arousal and the SCR for the 10 pictures in each condition were averaged for each participant. Turbine pictures were rated as significantly positive compared to the indifference point of 5 on the 1-to-9 SAM scale $(M=6.41, S D=.90, t(20)=7.30, p<.001)$; turbine average valence score was positive for all but one participant. They were also rated as not particularly arousing $(M=3.33$, $S D=1.33$ ) on a 1-to-9 SAM scale.

For ease of understanding, we describe the key results before we provide the detailed statistical analyses that supported them. Compared to other landscape pictures turbine pictures were rated as significantly more pleasant (having a more positive valence rating) than pylons but equally arousing, more pleasant and less arousing than power plants, and equally as pleasant and arousing as churches. Turbines were associated with higher SCRs than churches but there was no difference between SCRs to turbines, pylons and power plants. Compared to the landscape pictures, aversive pictures were rated as significantly more unpleasant as well as more arousing and they produced a higher SCR. Differences between turbine supporters and non-supporters 
were minor, although as expected, supporters rated turbine pictures as more pleasant than nonsupporters. Figure 4 depicts the ratings and Figure 5 depicts the differences between supporters and non-supporters.

The picture averages were submitted to three separate 5 (picture type: turbine, church, pylon, power plant, aversive) by 2 (attitude: supporters, non-supporters) mixed Analyses of Variance (ANOVAs, with the statistic $F$; the measure of effect size for these tests is $\eta^{2}$, read eta square). The main effect of picture type was significant for all of these analyses (valence: $F(4,76)=94.29, p<0.001$, partial $\eta^{2}=.83$ arousal: $F(4,76)=62.42, p<.001$, partial $\eta^{2}=.77$, SCR: $F(4,76)=9.17, p<0.01$, partial $\eta^{2}=.37$ ), but did not interact with attitude in any of them (valence: $F(4,76)=1.83, p>0.1$, partial $\eta^{2}=.09$ arousal: $F<1$, SCR: $\left.F<1\right)$. Planned contrasts revealed that turbines were rated more positively than pylons $(F(1,19)=11.14, p<.01)$, power plants $(F(1,19)=37.19)$, and the aversive pictures $(F(1,19)=183.38, p<.001)$ and as positively as churches $(F<1)$. Turbines were rated as less arousing than power plants $(F(1,19)=11.96, p<.01)$ and the aversive pictures $(F(1,17)=84.76, p<.001)$, and equivalent in arousal to churches $(F(1,19)=3.26, p>.05)$ and pylons $(F<1)$. Turbines were associated with elevated SCR compared to churches, $(F(1,19)=6.17, p<.05)$, equivalent SCR compared to pylons $(F<1)$ and power plants $(F<1)$, but lower SCR compared to the aversive pictures $(F(1,17)=8.21, p=.01)$. Supporters and non-supporters did not differ significantly in valence $(F(1,19)=3.64, p>.05)$ arousal $(F<1)$ or SCR $(F<1)$. The interaction between picture type and attitude was not significant in any of these ANOVAs. Still, because this comparison was of a-priori interest, we contrasted the valence and arousal ratings and SCR measurements taken from supporters and non-supporters. The only significant difference between the two groups was that supporters rated turbines more positively than non-supporters $(t(17)=3.16, p=.005)$. 
We evaluated the relationship between arousal ratings and physiological arousal with a regression model, with the predictors participant, picture type, and the average arousal ratings for each picture type. Average SCR for each picture type served as the dependent measure. The model was significant overall $(F(3,104)=7.00, p<.001)$. Only participant $(t=-3.48, p=.001)$ and picture type $(t=2.57, p<.05)$ significantly predicted average SCRs. Visual inspection suggested that this may have been be due to the presence of the aversive control pictures. A second model therefore included only the landscape pictures. In this second model, which was again significant overall $(F(3,104)=7.00, p<.001)$, only participant $(t=-4.77, p<.001)$ significantly predicted average SCRs. The effect of participant means that certain participants produced stronger SCRs across all picture types, as is well known. While aversive pictures were consistently associated with higher SCR and arousal ratings compared to landscape pictures, these two measures of arousal were not closely linked for landscape pictures.

\subsection{Relationship between the laboratory study and the questionnaire}

As predicted, more positive wind attitude scores correlated with more positive valence rating of turbine pictures (Pearson product-moment correlation coefficient $r=.54, p<.05$ ). Interestingly, wind turbine attitude and arousal associated with wind turbine pictures were not significantly correlated with each other for either participants' ratings $(r=-0.25, p>.2)$ or SCRs $(r=-0.09, p>.7)$. Because our arousal measurements do not distinguish between responses that stem from positive and negative feeling, this null effect could potentially be a consequence of both strong supporters and strong non-supporters exhibiting strong arousal. However, the finding of a negative correlation between valence and $\operatorname{SCR}(r=-.50, p<.05)$ and a negative, albeit non- 
significant, correlation between valence and arousal ratings $(r=-.18, p>.4)$ contradicts this potential interpretation: participants who rated turbines more positively reported numerically lower arousal and exhibited significantly lower SCRs.

\section{Discussion}

The method of assessment of emotional response has proved successful with the selfassessment manikin scales (SAM) being particularly easy to use, evident in highly reliable ratings as reported by Bradley and Lang (1994). The ratings of emotional intensity and valence showed that wind turbines were not judged particularly poorly compared with more familiar industrial constructions such as pylons and power plants. In fact this sample of respondents judged power plants and pylons as less pleasant than turbines, and power plants as also more arousing than turbines. Physiological arousal measurements did not differentiate between these constructions. Compared to churches turbines were rated as similarly pleasant but they were associated with stronger physiological arousal. As expected, the aversive control stimuli produced much more negative reactions both in terms of self-report and SCRs.

The physiological measurements supported the measure of self-assessed emotions of arousal and valence in that landscape pictures differed from aversive pictures on all of these measurements. Converging evidence is particularly important in emotion research, where the variables of key interest are not observable; this is even more true in situations where having two measures, one of which is outside volitional control, can help overcome report bias in politically motivated groups of stakeholders. Notably, although the results were similar across measures, there were differences as well, and arousal scores did not predict SCRs across participants, 
suggesting that collecting both kinds of measures could add to our understanding of participants' emotional response to wind turbines.

This is the first study that demonstrated that SCRs differentiate between landscape images of importance to landscape and urban planners. Together with Chang et al. (2008), these results underline the potential impact that psychophysiology could have for this area. Thus, although the current sample size was small and the sample was not representative of the UK population, our results could help motivate future studies with a larger, more representative sample.

There are currently no established instruments to assess attitudes towards wind turbines. Our questionnaire represents work in progress, and yielded some items that measured this variable with acceptable reliability and validity. There were small differences between supporters and non-supporters in the expected direction: supporters had more positive feelings towards turbines than non-supporters. However, this held true for all the scene types. It is possible that non-supporters are more sensitive to man-made additions to the landscape than supporters, perhaps reflecting a more general disposition towards preserving natural beauty in the countryside. Alternatively, their opposition to turbines may have influenced their mood overall, explaining why they also rated the aversive pictures as more aversive than supporters. Clearly, another avenue for extending this research is to include more opinionated participants, such as those who live in affected rural areas. It would be interesting to check whether the reliability of the self-reported emotions is reduced when such participants are included in the sample.

We have already discussed how the small, unrepresentative sample, which consisted mainly of individuals who were not personally affected by wind turbine technology. Moreover, 
supporters and non-supporters may not have had similar exposure to wind turbines in the real world thus limiting their ability to provide informed judgements and potentially compromising any comparison of results between these two groups. Future research should collect data on exposure and personal involvement. Another caveat has to do with the materials used. Using still pictures rather than video clips means that the full visual impact of the turbines cannot be represented. It can be argued that most participants will have assumed rotating blades when making assessments. Future research should therefore compare stills and video materials and evaluate whether the choice of materials changes the conclusions that can be drawn from still images, which are easier to use.

Using film clips could also help determine whether wind turbine noise would modulate the ranking of each of the industrial constructions relative to each other. The aerodynamic noise produced by rotating turbine blades is known to cause annoyance. This has been well researched to the point where dose-response relationships have been established for community response though it is concluded that these are "not particularly strong" and predicting individual responses is impractical (Fiumicelli, 2011). However, noise annoyance was found to be strongly correlated with a negative attitude to the visual impact of wind turbines on the landscape (Pedersen et al., 2009). The combined nuisance arising from visual and acoustic aspects was considered by participants the results may change the results, because churches and pylons do not produce significant noise nuisance when compared with wind turbines.

The current results are important because they help establish a methodology which can, in future, yield more accurate measurements of what the UK public feels about wind turbines compared to current survey tools. The visual impact on the landscape is considered at the planning stage for new wind turbine applications, and it is known to be of real importance to 
stakeholders (Knopper et al., 2014; Jones \& Eiser, 2010). Currently, stakeholders are required to imagine what the visual impact on the landscape would be, and report their attitudes using surveys known to be affected by proximity to proposed sites (Jones \& Eiser, 2010). The current methodology depends less on participants' imagination, and may be less affected by bias, and therefore holds promise in informing that decision making process. The method of assessment of the emotional response could with some adaption be used to gather useful information concerning likely impact of any particular wind farm. Suggested steps that would need to be followed are as follows:

1. Collect images of the proposed turbines. Images should reflect the geographical context of the sample, e.g. images from the UK would be presented to a representative sample from a UK population.

2. Using appropriate software add these images to pictures of the landscape viewed from a variety of locations chosen to represent particularly sensitive locations e.g. residential homes, public footpaths, public buildings etc. The size of the images and disposition of turbines should fairly reflect the proposed layout

3. Using the results from the previous step, prepare pairs of pictures with and without the wind turbine present (“before and after”)

4. Include at least 10 mildly-to-intensely aversive images (or up to $20 \%$ of the images, as in the current study). Such images can be drawn from the International Affective Picture System (IAPS, Lang, Bradley, \& Cuthbert, 2008). Responses to such images could help planners gain insight into the meaning of the emotional ratings responders provide. 
5. For each picture add two sets of self-assessment manikins labelled "pleasantness" (valence) and "Calmness" (reversed arousal scale)

6. Print out pictures, shuffle and add a top sheet requesting age and gender and bottom sheet requesting an indication of their support or opposition to the proposed wind farm and estimated distance to the nearest proposed turbine (if possible)

7. If possible obtain the views of all residents (using the electoral role) within $2 \mathrm{~km}$ (Bakker et al., 2012) of the centre of the proposed wind farm who are willing to complete the questionnaire and instruct them on recording their assessments.

8. Collect and analyse results overall. Compare before and after mean values of pleasantness and calmness to assess visual impact. Other analyses could also be completed depending on resource e.g. comparisons by distance from wind farm, age group and gender

It is considered that this structured and unbiased method of collecting data on the response to the visual impact of a proposed wind farm based on the protocol developed within this paper would lead to improved decision making and better outcomes. This needs to be tested of course and could form a further phase of the study.

\section{Conclusions}

To date, no study has used a psychophysiological approach to quantify objectively the intensity of emotions associated with the visual impact of wind turbines. We show that landscape pictures elicited measureable skin conductance response. Crucially, our participant sample rated wind turbines images to be as pleasant but less calming than churches, and more pleasant than 
other energy-production facilities. Compared to wind turbines, our sample rated pylons and power plants as significantly less pleasant, and power plants as more arousing. Putting the visual impact of these pictures in perspective, truly aversive pictures, such as a war scene or a bee sting, elicited a significantly stronger physiological arousal and were rated as less pleasant and more arousing. These pictures were associated with valence, arousal and SCR responses that were twice the intensity of the response to wind turbines. Several limitations of our sample should be acknowledged in interpreting these effects. First, our sample was small, and we may not have had sufficient power to detect subtle differences in ratings. Although we had sufficient power to detect a number of differences, the danger of both false negatives and false positives is real with such a small sample. Second, our preliminary study was conducted on a sample of students from a single university in the UK. Importantly, we do know how much exposure our sample had to wind turbines or other man-made constructions in the landscape. How the findings generalise to other members of the population or to other geographical location awaits further research. To be able to make policy recommendations future work should include a representative sample of the population.

There were only small differences in the responses of supporters and non-supporters of wind turbines and only the difference in valence ratings reached significance. The small sample size cautions against drawing firm conclusions from these null effects; instead, this study should be seen as a feasibility study helping establish a new methodology that could be used to assess the feelings of the general public about wind turbines.

Based on the successful methodology adopted in this study it is proposed that the approach could, with some adjustments, be used to assess the visual impact of wind turbines at the consultation stage of a new planning application. This would involve the comparison of 
suitably modified photographs of the proposed wind turbines before and after installation. The photographs we used were appropriate for a UK context, but would need to be adjusted for use in other countries. The self-assessment manikin rating scales could then be used to gather assessments of visual impact from the population likely to be most affected by the turbines. Ratings of pleasantness and calmness under the two conditions would then be used to assess the visual impact of proposed wind turbines. It is considered this has advantages over current methods which rely on an imagined scene without an easy-to-use rating scale. 


\section{References}

1. Bakker, R.H., Pedersen, E. B., van den Berg, G.P., Stewart, R.E, Lok, W. \& Bouma, J. (2012). Impact of wind turbine sound on annoyance, self-reported sleep disturbance and psychological distress. Science of the Total Environment, 425, 442-451.

2. Bradley, M. M, Codispoti, M., Cuthbert, B. N., \& Lang, P. J. (2001). Emotion and motivation I: defensive and appetitive reactions in picture processing. Emotion (Washington, D.C.), 1(3), 276-298. doi: 10.1037/1528-3542.1.3.276

3. Bradley, M. M., Cuthbert, B. N., \& Lang, P. J. (1990). Startle Reflex Modification: Emotion or Attention? Psychophysiology, 27(5), 513-522. doi:10.1111/j.14698986.1990.tb01966.x

4. Bradley, M. M., \& Lang, P. J. (1994). Measuring emotion: The self-assessment manikin and the semantic differential. Journal of Behavior Therapy and Experimental Psychiatry, 25(1), 49-59. doi:10.1016/0005-7916(94)90063-9

5. Cass, N., \& Walker, G. (2009). Emotion and rationality: The characterisation and evaluation of opposition to renewable energy projects. Emotion, Space and Society, 2, 62-69. doi: 10.1016/j.emospa.2009.05.006

6. Chang, C. Y., Hammitt, W. E., Chen, P. K, Machnik, L. \& Su, W. C. (2008).

Psychophysiological responses and restorative values of natural environments in Taiwan. Landscape and Urban Planning 85, 79-84.

7. Cohen, J, (1988). Statistical power analysis for the behavioral sciences (2nd ed.). Hillsdale, NJ: Lawrence Earlbaum Associates.

8. Department of Trade and Industry (2003). Attitudes and Knowledge of Renewable Energy amongst the General Public: Report Findings. Retrieved from http://www.dti.gov.uk/renewables/policy_pdfs/nationalreport.pdf

9. Devine-Wright, P. (2007). Reconsidering public attitudes and public acceptance of renewable energy technologies: a critical review. Manchester: School of Environment and Development, University of Manchester. Available at: http://www. sed. manchester. ac. uk/research/beyond_nimbyism.

10. De Vries, S., de Groot, M., \& Boers, J. (2012). Eyesores in sight: Quantifying the impact of man-made elements on the scenic beauty of Dutch landscapes. Landscape and Urban Planning, 105(1), 118-127. doi:10.1016/j.landurbplan.2011.12.005

11. Fiumicelli, D. (2011). Windfarm noise dose-response: a literature review. Acoustics Bulletin, 26-34.

12. Jacobson, M. Z., \& Archer, C. L. (2012). Saturation wind power potential and its implications for wind energy. Proceedings of the National Academy of Sciences, 109(39), 15679-15684. doi:10.1073/pnas.1208993109

13. Jasper, J. M. (1998). The Emotions of Protest: Affective and Reactive Emotions In and Around Social Movements. Sociological Forum, 13, 397-424. doi: 10.1023/A:1022175308081

14. Jones, C.R. \& Eiser, J. R. (2009). Identifying predictors of attitudes towards local onshore wind development with reference to an English case study. Energy Policy, 37 (11), 4604-4614.

15. Jones, C. R. \& Eiser J. R. (2010) Understanding 'local' opposition to wind development in the UK: How big is a backyard? Energy Policy, 38(6), 3106-3117.

16. Kandel, E. R., Schwartz, J. H., \& Jessell, T. M. (2000). Principles of neural science. New York: McGraw-Hill, Health Professions Division. 
17. Knopper, L. D.\& Ollson, C. A. Health effects and wind turbines: a review of the literature. Environmental Health (2011) 10:78. doi:10.1186/1476-069X-10-78

18. Knopper, L. D., Ollson, C.A, McCallum, L. C., Whitfield-Aslund, M.L, Berger, R. G., Souweine, K. \& McDaniel, M. (2014). Wind turbines and human health. Frontiers in Public Health, doi: 10.3389/fpubh.2014.00063

19. Kondili, E., \& Kaldellis, J. K. (2012). 2.16 - Environmental-Social Benefits/Impacts of Wind Power. In Ali Sayigh (Ed.), Comprehensive Renewable Energy (pp. 503-539). Oxford: Elsevier. Retrieved from http://www.sciencedirect.com/science/article/pii/B9780080878720002195

20. Krohn S., \& Damborg S. (1999). On Public Attitudes Towards Wind Power. Renewable Energy, 16(1), 954-960. doi:10.1016/S0960-1481(98)00339-5

21. Lang, P.J., Bradley, M.M., \& Cuthbert, B.N. (2008). International affective picture system (IAPS): Affective ratings of pictures and instruction manual. Technical Report A8. University of Florida, Gainesville, FL.

22. Lang, P. J., Greenwald, M. K., Bradley, M. M., \& Hamm, A. O. (1993). Looking at pictures: affective, facial, visceral, and behavioral reactions. Psychophysiology, 30(3), 261-273.

23. Maffei, L., Iachini,T., Masullo, M., Aletta, F., Sorrentino, F., Senese, V.P., \& Ruotolo, F. (2013) The effects of vision-related aspects on noise perception for wind turbines in quiet areas, International Journal of Environmental Research and Public Health, 10(5), 16811697.

24. McGowan, F., \& Sauter, R. (2005). Public opinion on energy research: a desk study for the research councils. Brighton, University of Sussex.

25. Maffei, L., Iachini,T., Masullo, M., Aletta, F., Sorrentino, F., Senese, V.P., \& Ruotolo, F. (2013). The effects of vision-related aspects on noise perception for wind turbines in quiet areas, International Journal of Environmental Research and Public Health, 10(5), 1681-1697

26. McGowan, F., \& Sauter, R. (2005). Public opinion on energy research: a desk study for the research councils. Brighton, University of Sussex.

27. Pachauri, R. K., \& Reisinger, A. (2007). Climate Change 2007: Synthesis Report. Contribution of Working Groups I, II and III to the Fourth Assessment Report of the Intergovernmental Panel on Climate Change. Intergovernmental Panel on Climate Change, 1 .

28. Pedersen E, Persson W. K. (2007). Wind turbine noise, annoyance and self-reported health and well-being in different living environments. Occupational Environment Medicine. 64(7),480-486.

29. Pedersen, E., Van den Berg, F., Bakkerand, R. \& Bouma, J. (2009). Response to noise from modern wind farms in the Netherlands. Journal of the Acoustical Society of America, 126(2) 634-643

30. Pheasant, R. J., Watts, G. R., \& Horoshenkov, K. V. (2009). Validation of a tranquillity rating prediction tool. Acta Acustica united with Acustica, 95(6), 1024-1031.doi: 10.3813/AAA.918234

31. Poortinga, W., Pidgeon, N., \& Lorenzoni, I. (2006). Public perceptions of nuclear power, climate change and energy options in Britain: summary findings of a survey conducted during October and November 2005. Retrieved from https://www.etde.org/etdeweb/details_open.jsp?osti_id=20712352 
32. Smith, C. A., \& Ellsworth, P. C. (1985). Patterns of Cognitive Appraisal in Emotion. Journal of Personality, 48(4), 813-838.doi: 10.1037/0022-3514.48.4.813

33. Swim, J., Clayton, S., Doherty, T., Gifford, R., Howard, G., Reser, J., Stern, P. \& Weber, E. (2009). Psychology and global climate change: Addressing a multi-faceted phenomenon and set of challenges. A report by the American Psychological Association's task force on the interface between psychology and global climate change. Retrieved from: http://www.apa.org/science/about/publications/climate-change.aspx

34. Watts, G., R. Maehr, A.M \& Talmi, D. Assessing visual impact of electrical power infrastructure and plant.

35. Watts, G. R., \& Pheasant, R. J. (2013). Factors affecting tranquillity in the countryside. Applied Acoustics, 74(9), 1094-1103. doi: 10.1016/j.apacoust.2013.03.007

36. Wolsink, M. (2000). Wind power and the NIMBY-myth: institutional capacity and the limited significance of public support. Renewable Energy, 21(1), 49-64.

doi:10.1016/S0960-1481(99)00130-5 
$\underline{\text { List of tables }}$

Table 1. Complete questionnaire with coding and factor loading.

Table 2. Correlations between questionnaire items that assessed wind turbine attitudes and the overall wind attitude score. 
Table 1. Complete questionnaire with coding and factor loading.

\begin{tabular}{|c|c|c|}
\hline & Question & Factor \\
\hline Q4 & How acceptable do you find the appearance of wind farms within a landscape?^ & 1 \\
\hline Q8 & I would be concerned if a wind turbine would be built in my neighbourhood. & 1 \\
\hline Q13 & Wind turbines spoil the views in many rural areas. & 1 \\
\hline Q1 & I consider myself to be knowledgeable about renewable energy. & 2 \\
\hline Q7 & More wind energy should be used on a worldwide scale.^ ${ }^{\wedge}$ & 2 \\
\hline Q12 & I am familiar with seeing wind turbines in my immediate environment.^^ & 2 \\
\hline Q14 & 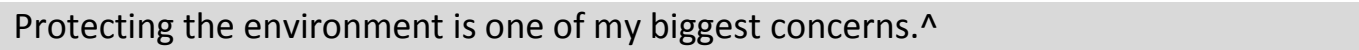 & 2 \\
\hline Q3 & I believe the concerns about climate change are exaggerated. & 3 \\
\hline Q11 & To which extent are you in favour of or opposed to the use of wind powers in the UK? & 3 \\
\hline Q2 & I believe that nuclear energy is the energy source of the future. & Distractor \\
\hline Q5 & Electricity pylons spoil the view in many rural areas. & Distractor \\
\hline Q6 & Electromagnetic radiation has a bad influence on human health. & Distractor \\
\hline Q9 & I am used to seeing nuclear power plants in the environment. & Distractor \\
\hline Q10 & We should use more solar energy. & Distractor \\
\hline Q15 & Churches spoil the views in many rural areas. & Distractor \\
\hline
\end{tabular}

Note. Questions 2, 5, 6, 10, 11, and 15 were distractor items. Three factors were identified but only factor one had good face validity where all questions (questions 4, 8 and 13) appeared to be measuring the same underlying latent variable. ${ }^{\wedge}$ These questions were reverse scored. 
Table 2. Correlations between questionnaire items that assessed wind turbine attitudes and the overall wind attitude score.

\begin{tabular}{|c|c|c|c|c|c|c|c|c|c|c|c|c|}
\hline $\begin{array}{l}\text { Question } \\
\text { number }\end{array}$ & mean & SD & Q1 & Q3 & Q4 & Q7 & Q8 & Q11 & Q12 & Q13 & Q14 & $\begin{array}{l}\text { Wind } \\
\text { attitude }\end{array}$ \\
\hline Q1 & 2.52 & 0.87 & 1.00 & 0.12 & $.38^{\star *}$ & $.36^{* *}$ & $.39^{* *}$ & 0.24 & 0.20 & 0.21 & $.58^{* *}$ & $.39^{* *}$ \\
\hline Q3 & 4.10 & 0.77 & & 1.00 & 0.11 & 0.15 & -0.10 & 0.14 & -0.14 & 0.14 & 0.24 & 0.06 \\
\hline Q4 & 3.28 & 0.88 & & & 1.00 & 0.24 & $.53^{* *}$ & 0.10 & -0.04 & $.39^{* *}$ & $.28^{*}$ & $.74^{* \star}$ \\
\hline Q7 & 4.18 & 0.87 & & & & 1.00 & 0.08 & $.30^{*}$ & 0.17 & 0.07 & $.40^{* *}$ & 0.15 \\
\hline Q8 & 3.67 & 1.11 & & & & & 1.00 & 0.12 & 0.11 & $.55^{* *}$ & $.284^{*}$ & $.85^{* *}$ \\
\hline Q11 & 3.93 & 0.82 & & & & & & 1.00 & -0.13 & 0.20 & 0.22 & 0.18 \\
\hline Q12 & 2.22 & 1.32 & & & & & & & 1.00 & -0.15 & $.36^{* *}$ & -0.04 \\
\hline Q13 & 3.32 & 1.24 & & & & & & & & 1.00 & 0.23 & $.83^{* *}$ \\
\hline Q14 & 2.87 & 0.98 & & & & & & & & & 1.00 & $.320^{*}$ \\
\hline Wind attit & 3.35 & 10.50 & & & & & & & & & & 1.00 \\
\hline
\end{tabular}

Note. Questionnaire data averaging across 60 participants. Participants answered the questions on a 5-point rating scale and the relevant items were reverse-scored (see Table 1). * Correlation is significant at the 0.01 level (2-tailed). $* *$ Correlation is significant at the 0.05 level (2-tailed). 


\section{List of figures:}

Figure 1: Examples of the pictures used in the laboratory experiment. Three examples each of the turbine, pylon, power plant and churches pictures are presented.

Figure 2: A schematic drawing of one step in the laboratory experiment. The drawing shows the sequence of picture presentation and their timing as well as the emotional valence and emotional arousal SAM rating scales. Ratings were self-paced. The tranquillity ratings are not presented.

Figure 3: Scree plot. Eigenvalues indicated that there were three possible factors. The scree plot was interpreted as also indicating three factors as there are three points before the point at which it begins to flatten.

Figure 4: Ratings and skin conductance response (SCR) associated with five picture types: sceneries with turbines, churches, power plants and pylons, and aversive control pictures (starred differences are statistically significant $p<0.05)$.

(a) Self-reported arousal and SCR

(b) Valence ratings (pleasantness)

Figure 5: Self-reported valence and arousal ratings and skin conductance responses (SCR) associated with five picture types: sceneries with turbines, churches, power plants and pylons, and aversive control pictures. Data depicted as a function of wind turbine attitude as established during the questionnaire study (starred differences are statistically significant $p<0.05$ ).
(a) Valence ratings
(b) Arousal ratings
(c) SCR 
Figure 1
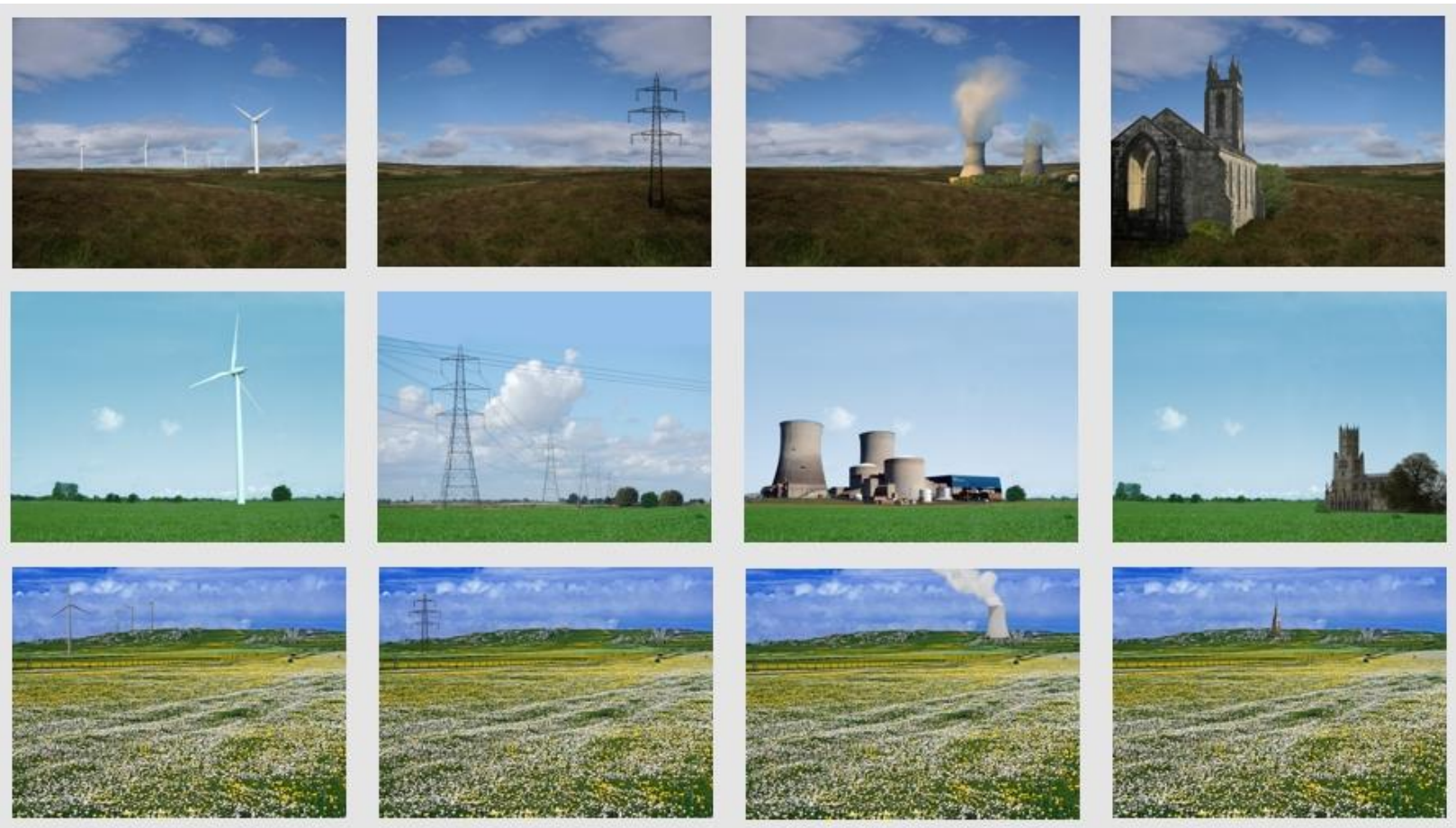
Figure 2

Figure 2: A schematic drawing of one step in the laboratory experiment, showing the sequence of picture presentation and their timing as well as the emotional valence and emotional arousal SAM rating scales. Ratings were self-paced. The tranquillity ratings are not presented.

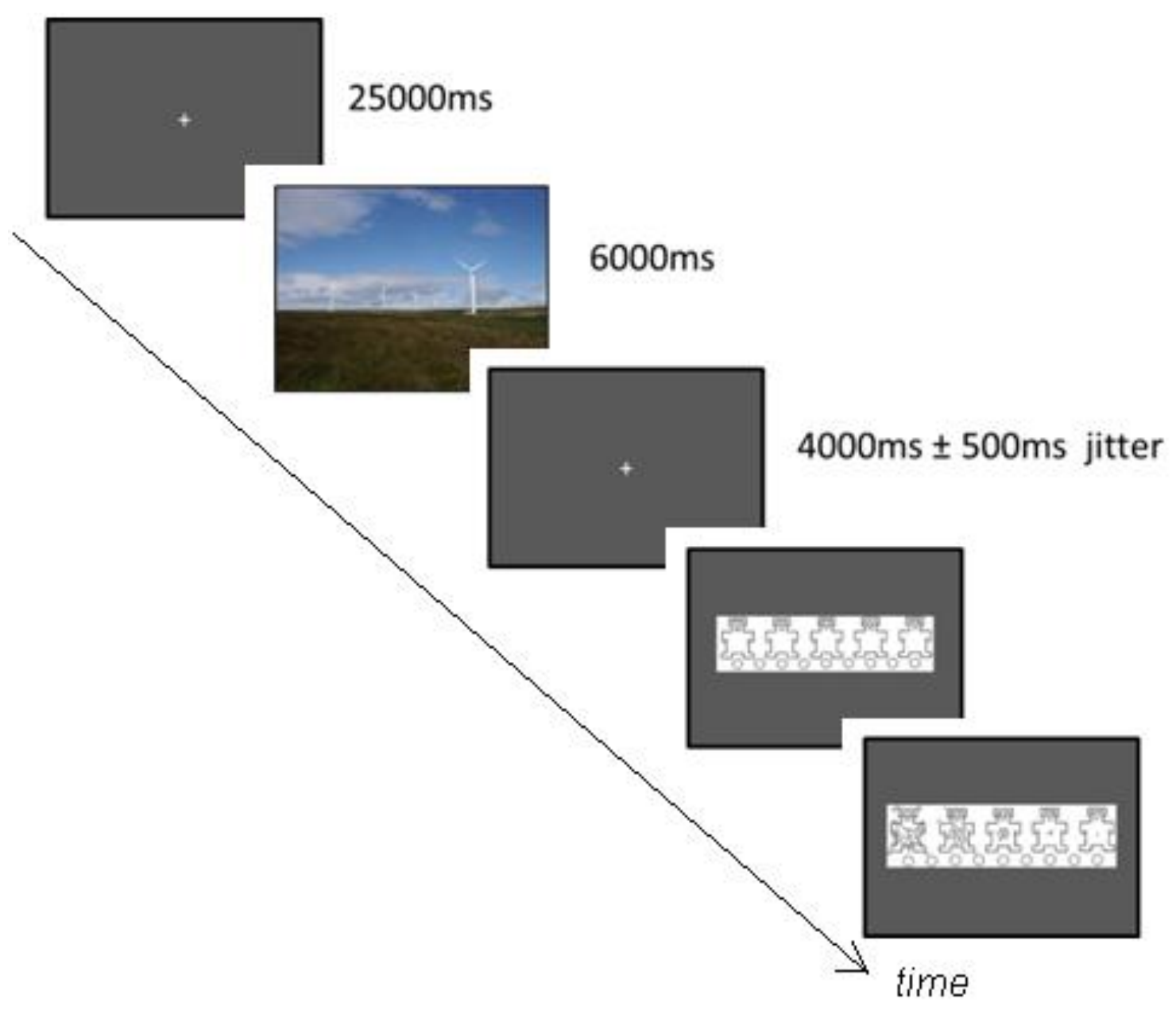


Figure 3

Figure 3: Eigenvalues indicated that there were three possible factors. The scree plot was interpreted as also indicating three factors as there are three points before the point at which it begins to flatten.

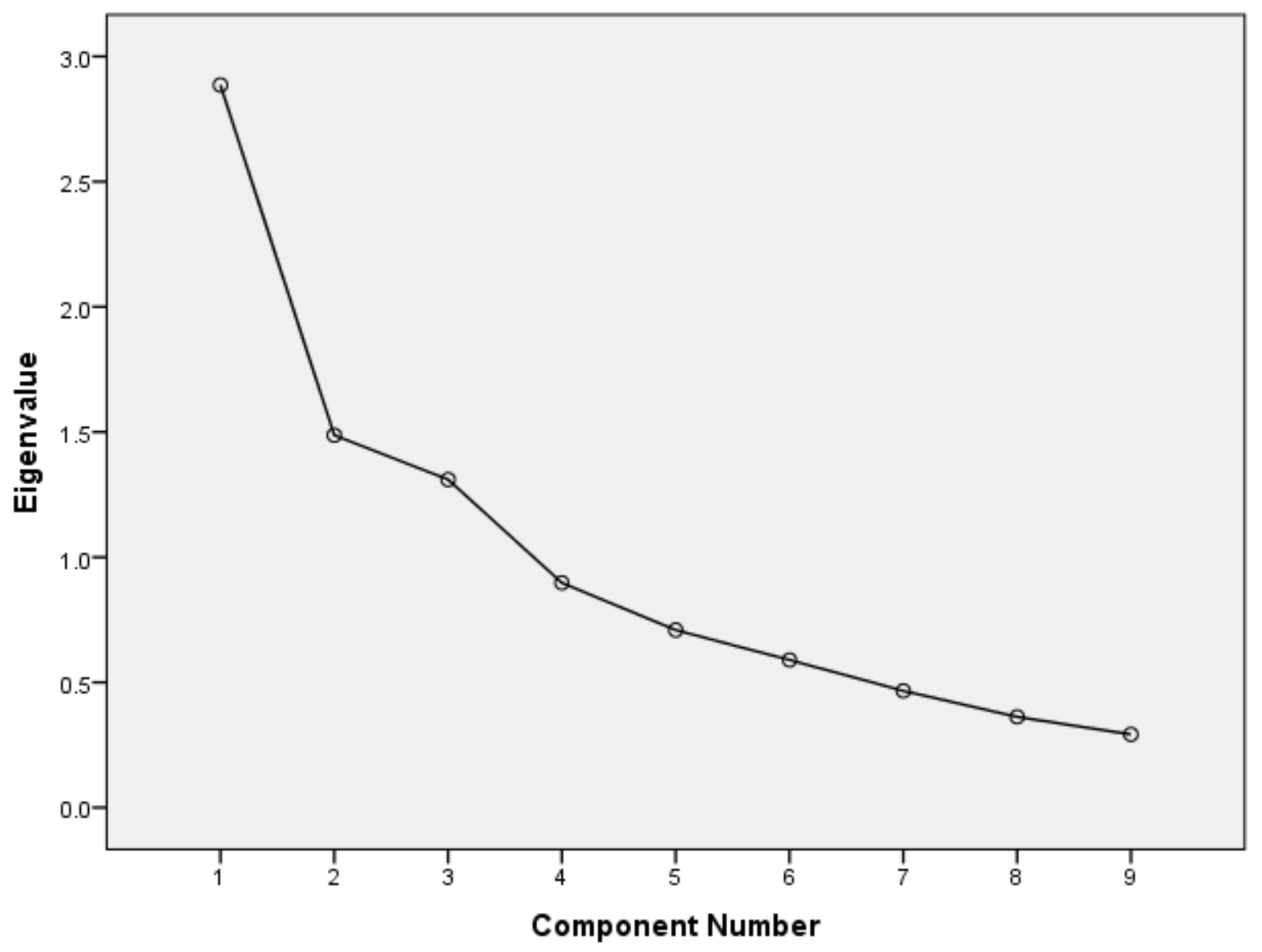


Figure 4

\section{Valence}

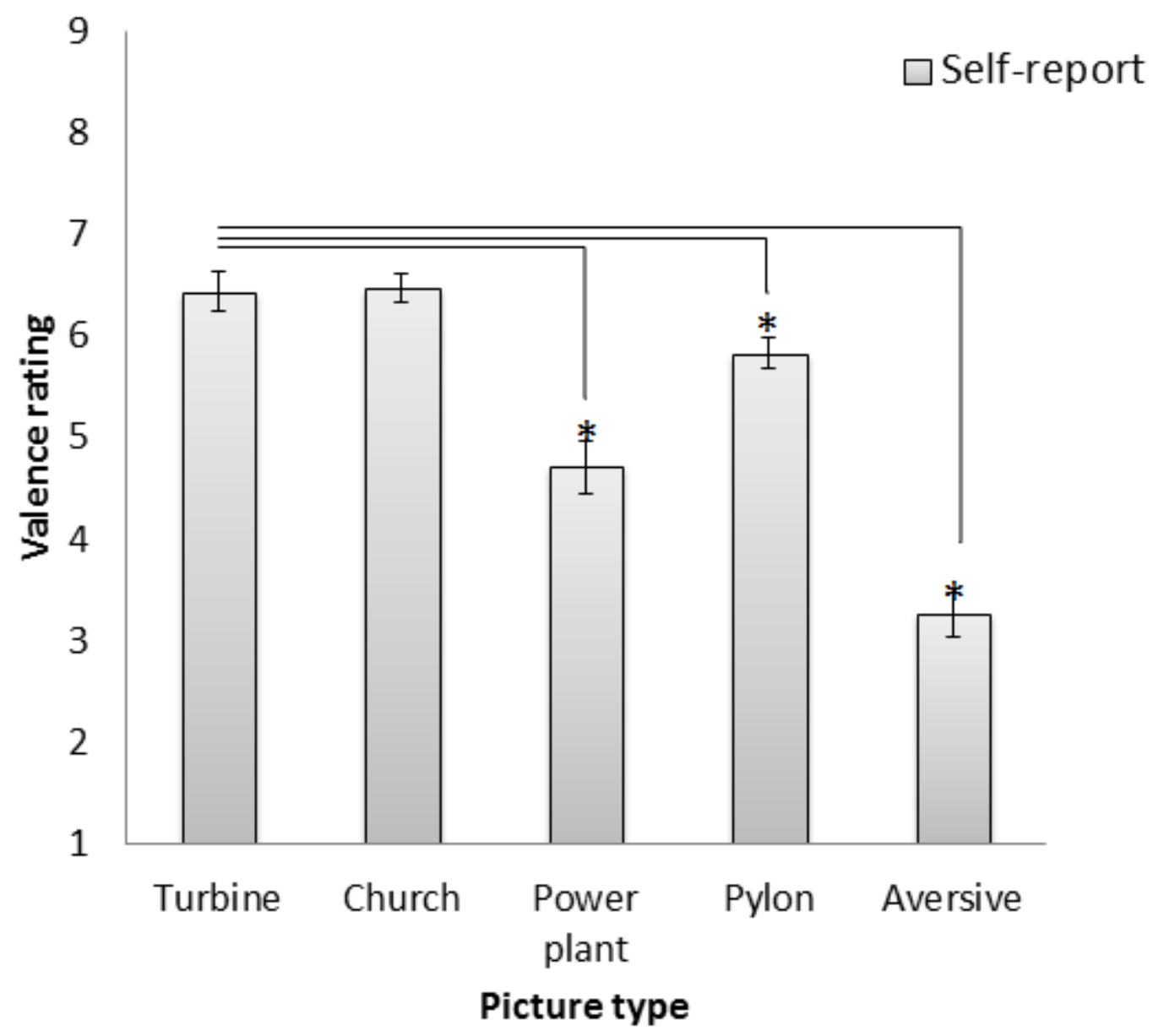


Arousal

$\square$ Self-report

- Phsyiological arousal

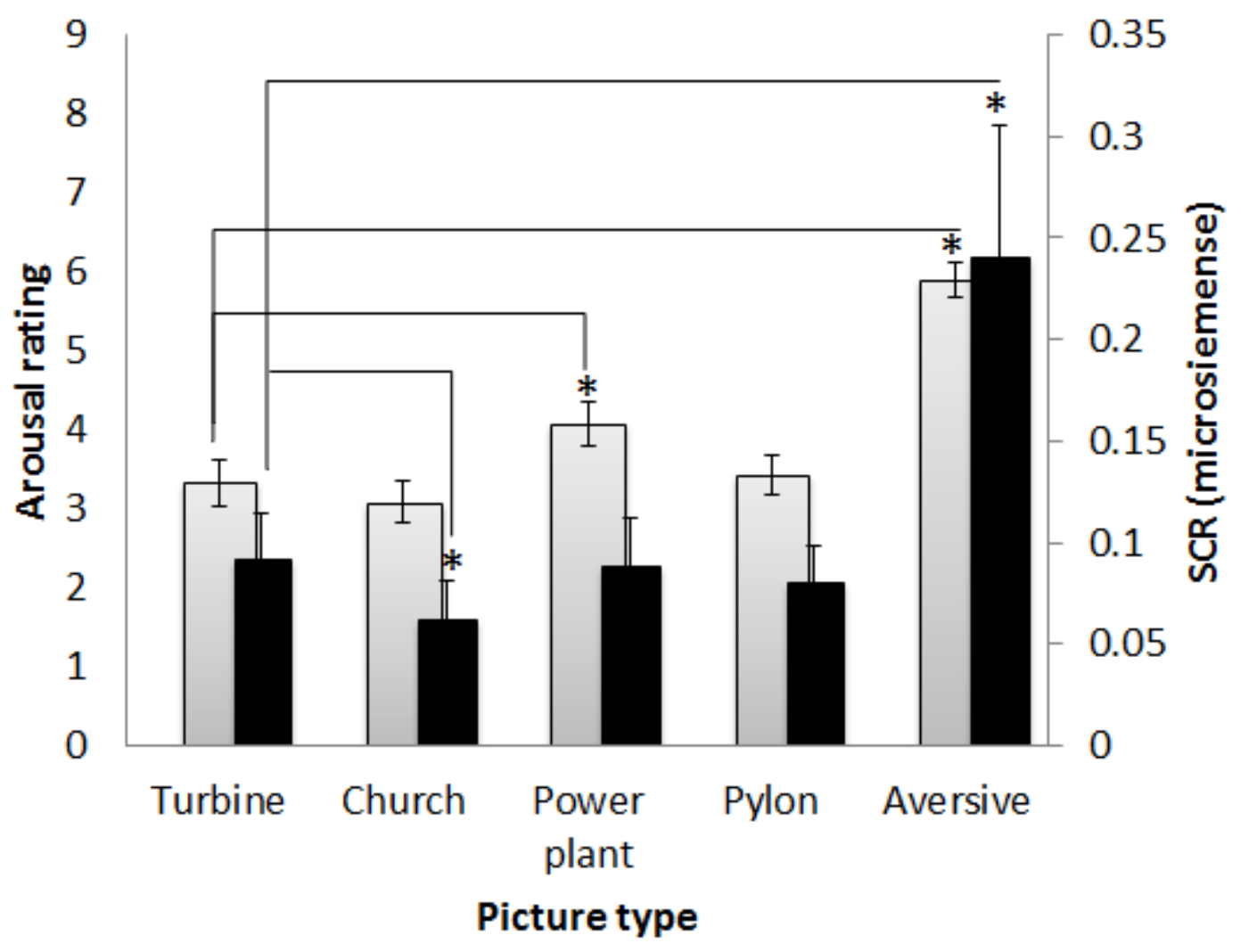


Figure 5

\section{Valence: self report}

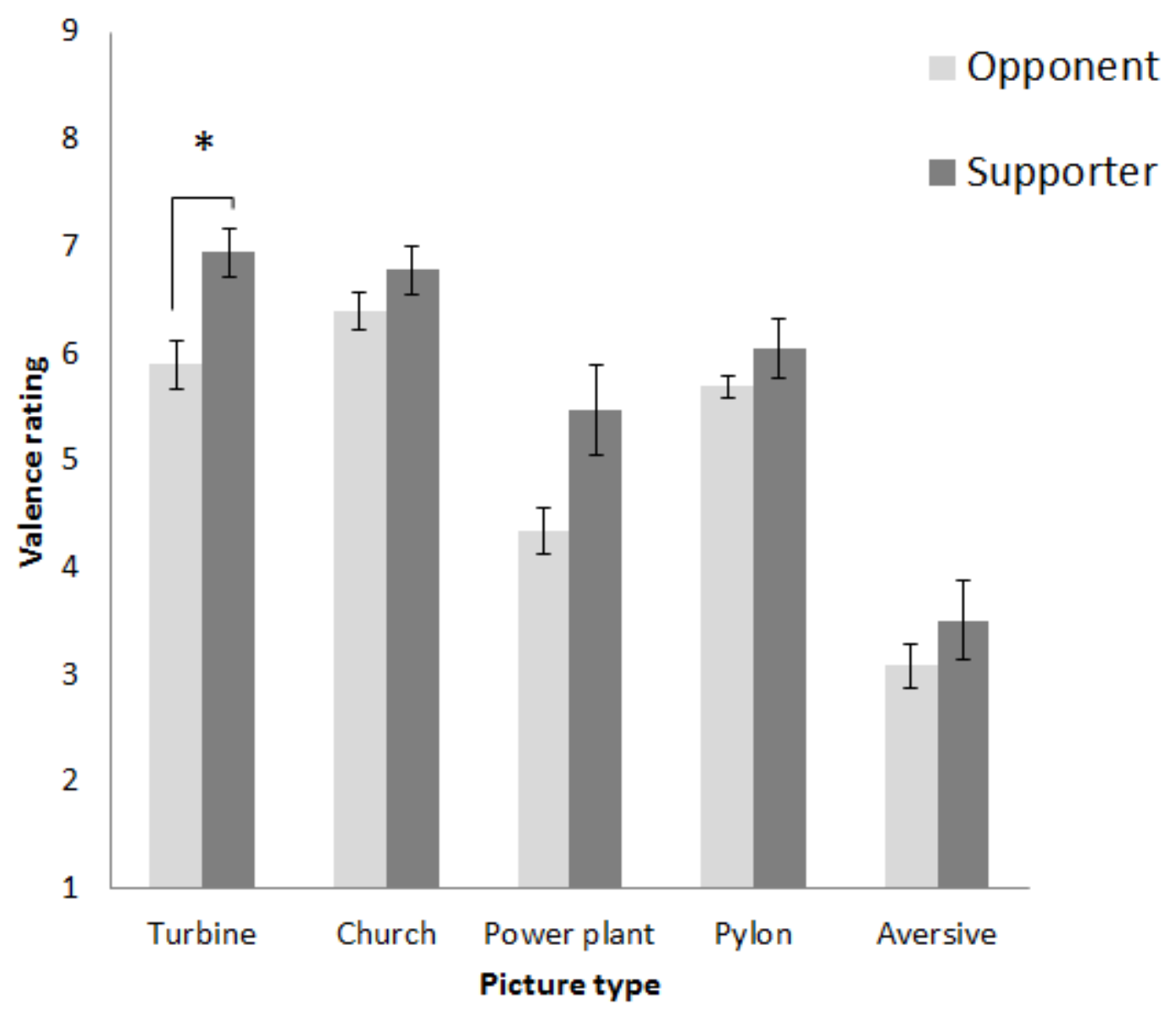


Physiological arousal

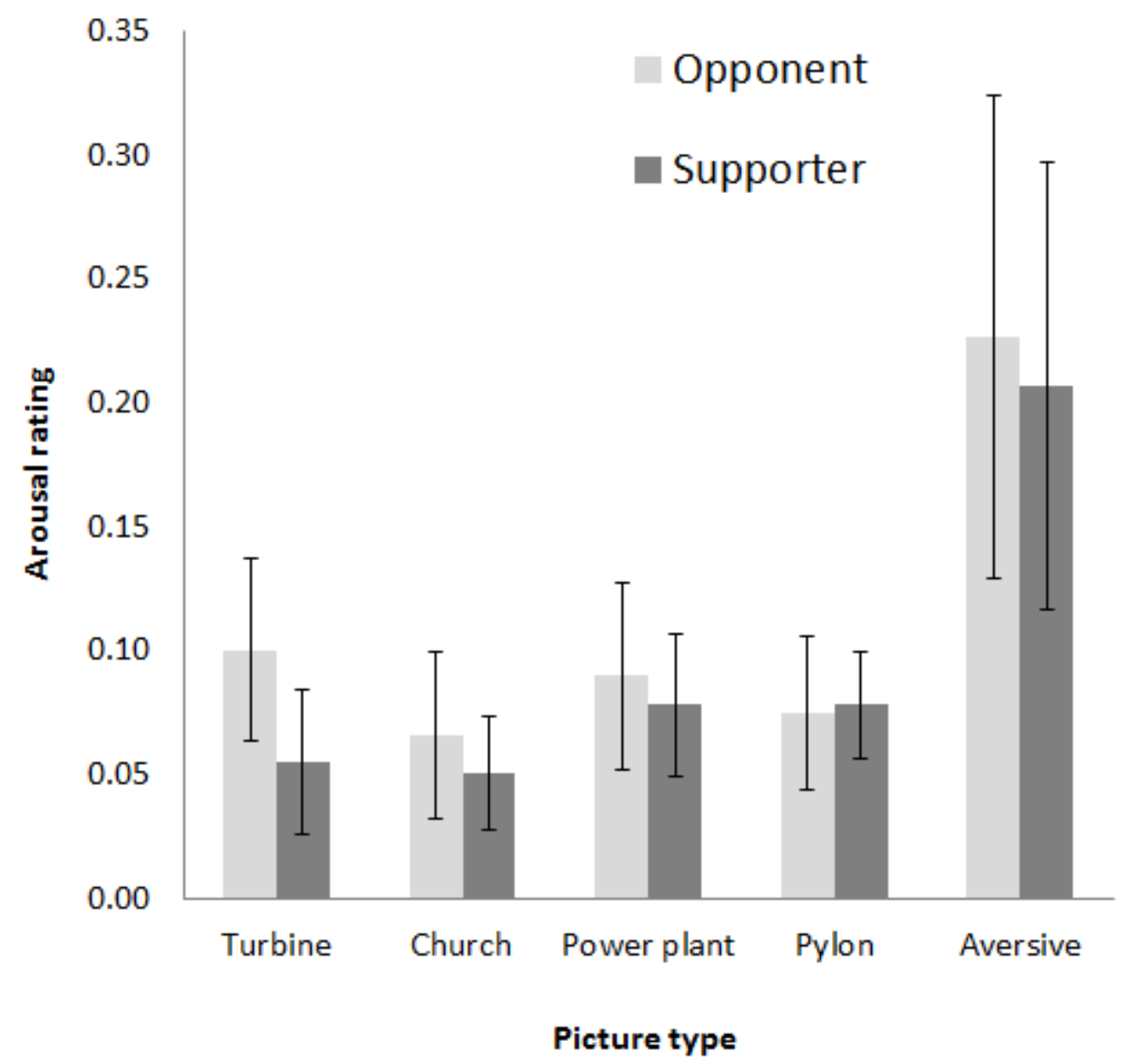

